\title{
ULTRA-SOUND ASSESSMENT OF FETAL KIDNEY VOLUME AND RENAL BLOOD FLOW VELOCIMETRY IN INTRAUTERINE GROWTH RESTRICTION
}

\author{
By \\ Mahmoud Radi Mohammad, Abd Al-Monem Mohammad Zakaria, \\ Ahmed Abd El-Fatah Mahmoud Abo-Rashed and Abd Al-Monsef Abd \\ Al-Hamid Sedek \\ Department of Obstetrics \&Gynecology, Faculty of Medicine, Al-Azhar University, Cairo \\ Corresponding Author: Mahmoud Radi Mohammad,
}

Mobile: 01025164195, E-mail: mrady305@yahoo.com

\begin{abstract}
Background: Intrauterine growth restriction ( IUGR ) refers to a condition in which an unborn baby is smaller than it should be because it is not growing at a normal rate inside the womb. Delayed growth puts the baby at risk of certain health problems during pregnancy, delivery and after birth.

Objective: To investigate the correlation between kidney volume and renal artery Doppler in intra-uterine growth restriction.

Patients and Methods: This was a prospective randomized descriptive study on 64 pregnant females devided in to two equal groups: Group A: Pregnant females with restricted fetal growth and Group B: females with normal pregnancy. Fetal renal volume was measured by 3-D ultrasound. Renal artery, umbilical artery and middle cerebral artery Doppler indices were measured for each fetus in both groups.

Results: The mean total fetal renal volume was $10.26 \pm 2.62$ in group A and 16.85 \pm 5.35 in group B. Head circumference, abdominal circumference and estimated fetal weight were positively correlated with the total renal volume "TRV" in both groups, with a statistically significant of group B". Umbilical artery resistance index was inversely correlated with the total renal volume in group B. The middle cerebral artery resistance index did not show a significant correlation with the TRV in group A in contrast to the control group where a significant negative correlation existed between the two parameters.
\end{abstract}

Conclusion: Intrauterine growth restriction appears to be associated with a decrease in the fetal renal volume.

Keywords: Ultra-sound assessment of fetal kidney volume, renal blood flow velocimetry, intrauterine growth restriction.

\section{INTRODUCTION}

The best definition of intrauterine growth restriction is failure of a fetus to reach its growth potential. The causes can be many, but most often involve poor maternal nutrition or lack of adequate oxygen supply to the fetus (Wendel, 2010).

This definition means that failure to grow along a consistent percentile is more important than absolute size. In other words, a fetus with an abdominal circumference (AC) on the $90^{\text {th }}$ percentile 
at 28 weeks gestation and the 50th percentile at 36 weeks gestation is more likely to be growth restricted than a fetus which is on the 5th percentile at 28 weeks and again at 36 weeks. Other association of growth restriction is decreased amniotic fluid volume, estimated fetal weight and abnormal umbilical artery waveform may also be incorporated into the definition (Baschat et al., 2012).

Any insult occurring in the fetal growth period can result in fetal growth abnormalities. The earlier the insult is, the more likely it will affect the cellular hyperplasia stage of the fetal growth, thereby resulting in symmetrical reduction of the organ size and a symmetrical IUGR fetus. In contrast, if the insult happens later in the gestation (after cell hyperplasia stage), the cell size will be affected, therefore resulting in asymmetrical IUGR (Reeves and Galan, 2012).

Many factors are involved in the etiology of IUGR, i.e: Fetal causes: Chromosomal Aneuploidies (Andzane et al., 2015), structural anomalies: (all major structural defects are associated with an increased risk of having a small fetus) and Fetal Infections: Common infections include TORCH (Adanu, 2010).

Multiple pregnancies are known to have fetal growth restriction as one of the common complications, and account for up to $3 \%$ of all cases of IUGR (Miller et al., 2012).

Other causes are related to the mother like maternal age, nutritional status, chronic disease....etc.

Multi-vessel Doppler examination is able to accurately depict the progression in IUGR fetuses. Dynamic fetal variables (movement, tone, breathing and amniotic fluid volume) utilized for biophysical profile (BPP) and heart rate reactivity remain normal longer in the progression of IUGR Fetuses. Renal volume and its blood flow are considered as new tools for assessment of chronic fetal hypoxia. In cases of fetal malnutrition resulting in intrauterine growth restriction more blood flow is directed to the organs like brain and heart depriving other organs like kidney from its nutrition. Normally kidney receives approximately $2-3 \%$ of cardiac output as fetal renal artery shows increased resistance in early trimester. Towards the term, the resistance in the renal artery falls thus directing more blood towards the kidneys which is reflected by increase in end diastolic velocity and mean velocity. In fetal hypoxemia, significant reduction i.e. by approximately $25-50 \%$ of baseline values is seen. In these cases, fetal renal Doppler shows increased resistance in the form of raised pulsatility and resistivity index. Thus stating direct relationship between fetal hypoxia and renal artery resistance (Baschat et al., 2012).

The present work aimed to investigate the correlation between kidney volume and renal artery Doppler in intra-uterine growth restriction.

\section{PATIENTS AND METHODS}

This prospective randomized descriptive study was carried out to pregnant women during their antenatal care in Obstetrics \& Gynecology clinic in Sayed Galal university hospital, Faculty of Medicine, Al-Azhar University, Cairo (October 2016 till October 2019). 
We selected the patients according to the following criteria (inclusion criteria): Age 20-35 years, Gestational age: more than 20 weeks, all patients should have normal kidney and liver functions. We excluded any patient with multi-fetal pregnancy or any uterine anomaly (exclusion criteria). An informed consent from every patient was taken. Thirty two females with restricted fetal growth (group A) and thirty two with normal pregnancy (group B). The study was approved by ethical committee.

Fetal biometry was done to categorize each group (criteria of diagnosis of IUGR) by estimation of fetal weight (EFW) which must be $<10^{\text {th }}$ percentile for gestational age. In cases with asymmetric
IUGR: abdominal circumference was< other biometric parameters, while in symmetric IUGR, fetus was uniformly small for gestational age (GA). Each patient was examined using 3-D ultrasound and Doppler to detect biophysical profile, renal artery Doppler, kidney volume, umbilical and middle cerebral artery Doppler.

\section{Data analysis:}

The data were collected, coded, revised, verified and computerized. Statistical analyses were done using SPSS statistical package version 16. (IBM Corp, Chicago, IL, USA). Quantitative variables as mean and standard deviation (SD) were carried out by the student t-test of two independent samples.

\section{RESULTS}

Comparison between both study groups concerning gestational age at randomization group A was $32.8 \pm 2.6$ and $33.4 \pm 3.2$ in group B with a nonsignificant value. The mean total renal volume was significantly lower in group
A compared to group B. The mean UA-RI showed a significant value. The mean MCA-RI showed a significant value. The mean renal A-RI showed non-significant values (Table 1).

Table (1): Gestational age at randomization, renal diameters and volume by 3D-U/S and Doppler indices among the two study groups

\begin{tabular}{|l|c|c|c|c|c|}
\hline \multirow{2}{*}{ Garameters } & \multicolumn{2}{|c|}{ Group A } & \multicolumn{2}{c|}{ Group B } & \multirow{2}{*}{ P value } \\
\cline { 2 - 5 } & Mean & SD & Mean & SD & \\
\hline GA & 32.8 & 2.6 & 33.4 & 3.2 & $>0.05$ \\
\hline Longitudinal & 34.1 & 3.2 & 40.8 & 2.2 & $<0.001$ \\
\hline AP & 16.7 & 2.1 & 20.1 & 1.9 & $<0.001$ \\
\hline Transverse & 16.5 & 2.3 & 19.1 & 1.2 & $<0.001$ \\
\hline Total renal Volume & 10.26 & 2.62 & 16.85 & 5.35 & $<0.001$ \\
\hline UA-RI & 0.71 & 0.04 & 0.67 & 0.04 & $<0.001$ \\
\hline MCA-RI & 0.71 & 0.06 & 0.88 & 0.03 & $<0.001$ \\
\hline Renal A-RI & 0.68 & 0.05 & 0.71 & 0.03 & $>0.01$ \\
\hline
\end{tabular}




\section{DISCUSSION}

3D volume examination has been used in various different research settings in order to assess their value in the clinical setting, e.g. in the estimation of fetal lung volume to predict neonatal lung hypoplasia. A possible clinical application of assessing fetal renal volume could be to distinguish fetal renal pathology from physiology in order to predict neonatal outcome. The reproducibility of 3D ultrasound in obtaining renal volume has been proved to be accurate in in-vitro and in vivo models, and reference charts of fetal renal volume have been established by 3-D ultrasound (Blanco et al., 2011).

The main strength of our study was the use of $3 \mathrm{D}$ ultrasound in the measurement of fetal renal volume. The main advantage of 3D ultrasound was its accuracy, but there were some limitations for its use (not routinely available, expensive, and time consuming). Therefore, different research settings use the easier way to measure the renal volume by two dimensional ultrasonography (Bijnenset al., 2015).

Concerning the maternal age, maternal body mass index (BMI), gestational age, associated maternal chronic hypertension, diabetes mellitus, heart disease, sickle cell anemia and systemic lupus erythomatosis, there was no significant statistical difference between both groups.

Increased placental vascular resistance and decreased cerebral resistance are known to be associated with reduced fetal growth. In our study, UA-RI was associated with reduced renal volume denoting that the renal volume depended on placental blood flow. We did not find any correlation between the renal volume and decreased cerebral vascular resistance. It may be that redistribution with decrease in MCA-RI is a later sign in IUGR that was not yet eminent in our study (Stergiotouet al., 2015).

El Behery and her Colleagues (2012) studied the umbilical, middle cerebral, fetal renal artery Doppler and fetal kidney volume in healthy and growth restricted fetuses after 26 weeks of gestation. They found that combined and relative fetal kidney volume was significantly reduced in growth restricted fetuses than in normally grown fetuses $29 \%$ for the former and $18 \%$ for the latter. All fetal biometric indices were positively associated with combined kidney volume. The largest effects were found for estimated fetal weight and abdominal circumference after adjustment for gestational age. No correlation exists between umbilical or middle cerebral artery Doppler and fetal renal volume. A significant negative correlation was found between fetal renal artery pulsatility index and fetal renal volume after adjustment for abdominal circumference.

Sharma and his Colleagues (2016) demonstrated that smaller antero-posterior and transverse kidney diameters observed in small for gestational age fetuses resulted in altered renal morphologic characteristics, producing sausage-shaped kidneys. They also demonstrated that fetuses with intrauterine growth restriction had significantly smaller renal volumes than did healthy fetuses from 20 wks. gestation to term.

A possible clinical application of assessing fetal renal volume could be to detect fetuses that may suffer from renal troubles later in life. In fact, fetal renal 
volume could be the sole marker in predicting the need for postnatal follow up and treatment.

This study underlined the importance of fetal growth and growth characteristics for determination of kidney size. Because the number of nephrons is largely determined intra-uterine, suboptimal kidney growth in fetal life may have lifelong consequences (Cappellettiet al., 2013).

\section{CONCLUSION}

The intrauterine growth restriction appeard to be associated with a decrease in the fetal renal volume. This study supported the hypothesis that intrauterine growth restriction may be linked to renal disease and hypertension in late life.

\section{REFERENCES}

1. Adanu RMK (2010): Malaria in pregnancy. In: Queenan JT, Hobbins JC, Spong CY, editors. Protocols for high-risk pregnancies: an evidence-based approach. 5th ed. Pbl. Oxford: Wiley-Blackwell, 44(4):159-162.

2. Andzane D, Gapatins I and Miskova A (2015): Intrauterine growth restriction: distribution, risk factors, management of labour and outcome. Int J Reprod Contracept Obstet Gynecol., 4:1117-21.

3. Baschat AA, Galan HL and Gabbe SG (2012): Intrauterine growth restric $\neg$ tion. In: Gabbe SG, Neibyl JR, Simpson JL, editors. Obstetrics normal and problem pregnancies. Pbl. Philadelphia: Elsevier, Pp. 706-41.

4. Bijnens M, Cruz-Lemini F, Figueras $\mathbf{E}$ and Egratacos F (2015): Maternal subclinical vascular changes in fetal growth restriction with and without pre 7 eclampsia. Ultrasound in Obstetrics \& Gynecology, 46(6):706.
5. Blanco PG, Rodriguez $R$ and Rube $A$ (2011): Doppler ultrasonographic assessment of maternal and fetal blood flow in abnormal post-term pregnancy. Reprod Sci., 126:130e5.

6. Cappelletti M, Giannelli S, Martinelli A, Cetin I, Colombo E, Calcaterra F, Mavilio D and Della Bella S (2013): Lack of activation of peripheral blood dendritic cells in human pregnancies complicated by intrauterine growth restriction. Placenta, 34(1):35-41.

7. El Behery MM, Ibrahiem MA, Siam S and Seksaka MA (2012): Fetal Renal Volume and Fetal Doppler in Normal and Growth Restricted Fetuses: Is There a Correlation? Gynecol Obstet., 2:118-123.

8. Miller J, Chauhan SP and Abuhamad AZ (2012): Discordant twins: diagnosis, evaluation and management. Am J Obstet. Gynecol., 206(1):10- 20.

9. Reeves S and Galan HL (2012): Fetal growth restriction. In: Berghella $\mathrm{V}$, editor. Maternal-fetal evidence based guidelines. 2nd ed. Pbl. London: Informa Health Care, Pp. 329-44.

10. Sharma D, Farahbakhsh N, Shastri S and Sharma $P$ (2016): Intrauterine growth restriction - part 2. J Matern., Fetal, Neonatal Med., 8(3):1-12.

11. Stergiotou B, Bijnens $M$, Cruz-Lemini F and Egratacos F (2015): Maternal subclinical vascular changes in fetal growth restriction with and without pre 7 eclampsia. Ultrasound in Obstetrics \& Gynecology, 46(6):706.

12. Wendel GD (2010): Cytomegalovirus, genital herpes, rubella, syphilis and toxoplasmosis. In: Queenan JT, Hobbins JC, Spong CY, editors. Protocols for high-risk pregnancies: an evidence-based approach. 5th ed. Pbl. Oxford: Wiley-Blackwell, Pp. 44(4):169-172. 
إستخدام الموجات فوق الصوتيه فى تقييم حجم كلى الجنين

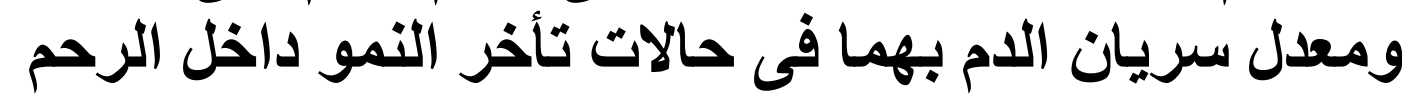

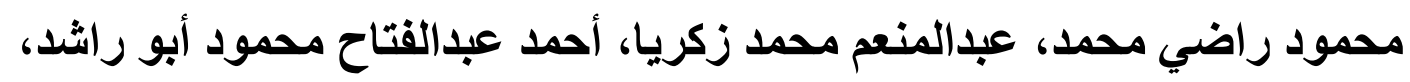

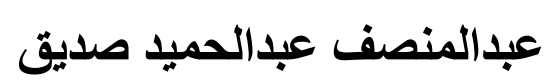

قسمي جراحة المخ والأعصاب* والأشعة***،كلية الطب، جامعة الأزهر

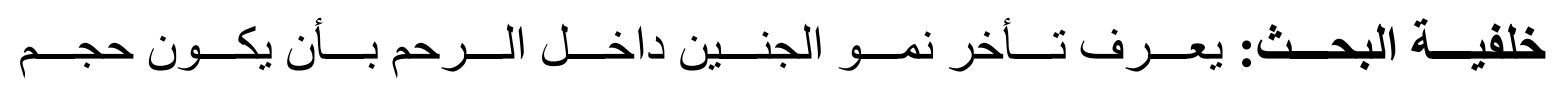

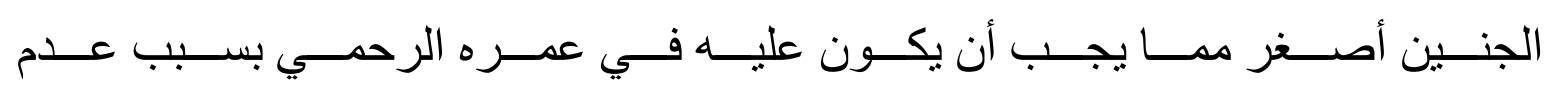

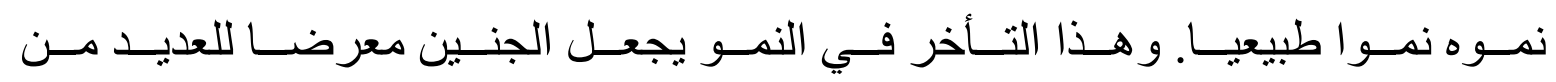
الدخاطر الصحية أثناء الحمل و الو لادة وأيضا في حياته المستقبليه.

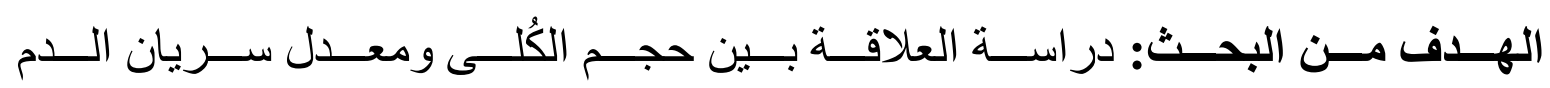
بهما في الأجنة الذين يعانون من تاخر النمو داخل الرحم.

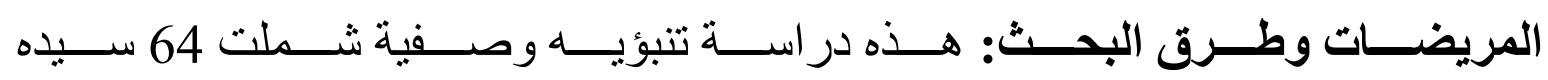
من الحو امل قسمت إلي مجمو عتين متساويتين:

ـ المجموعـة (أ): و وهـن سـيدات حوامـل وتعــانين أجنــتهن مــن سـوء النمـو

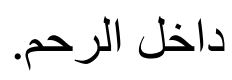

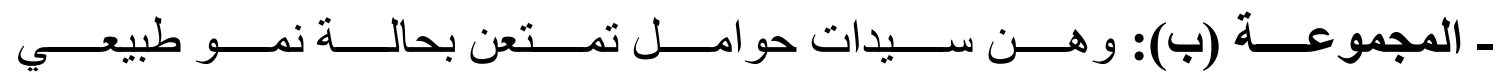

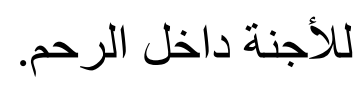

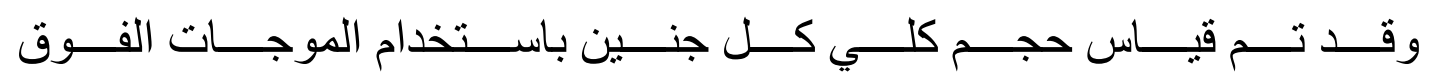

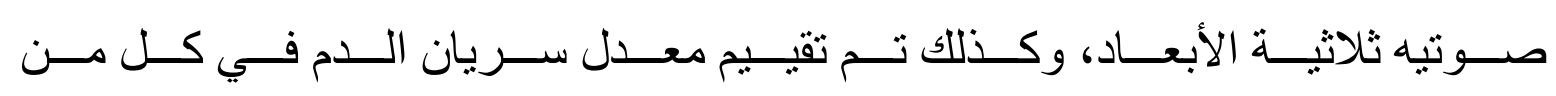

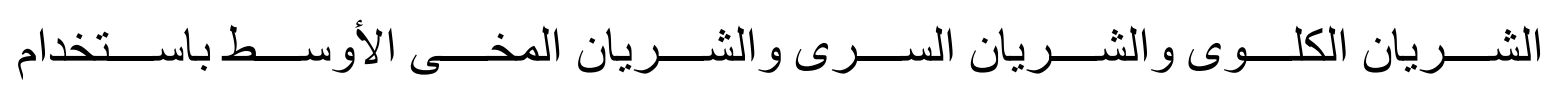

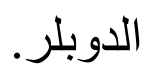


ULTRA-SOUND ASSESSMENT OF FETAL KIDNEY VOLUME AND...

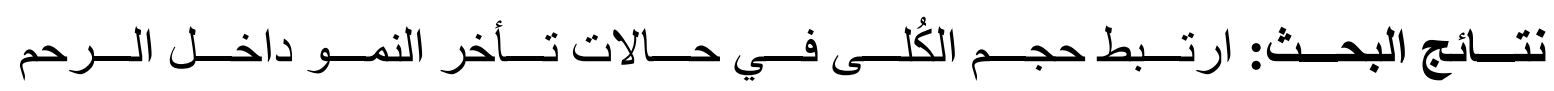

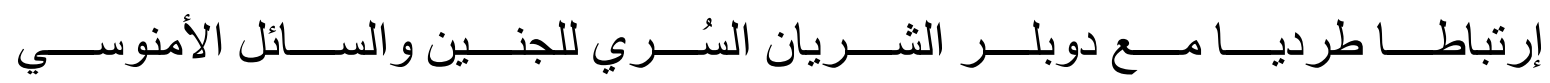

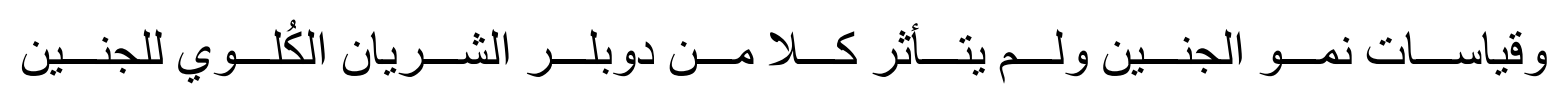

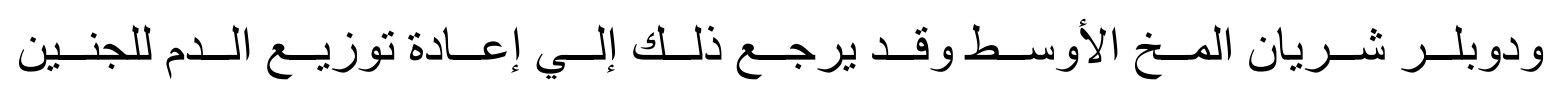
في حالات تأخر النمو داخل الرحم.

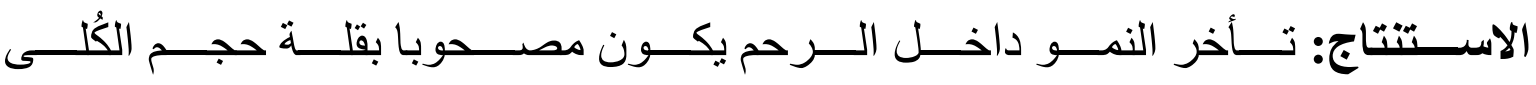

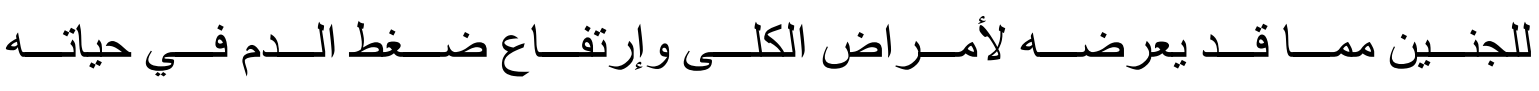
المستقبلية. 